\section{Toxigenicity of Treponema hyodysenteriae, Another Emerging Enteropathogen}

Recent papers have pointed out the possible role of intestinal spirochaetes in human pathology $(1,2,3)$. Treponema hyodysenteriae, a most representative member of this group which is widely recognized as an important agent in swine dysentery, has recently been isolated from different specimens of diarrheic patients (4). The biological profile of this emerging enteropathogen has yet to be completely elucidated, and some approaches indicate the possible factor(s) responsible for disease production. Firstly, it should be noted that lipopolysaccharides from $T$. hyodysenteriae may have endotoxic activity and may be functional in the pathogenicity of swine dysentery (5). Furthermore, a correlation between the haemolytic pattern and enteropathogenicity of the culture filtrates of the bacterium has been emphasized $(6,7,8,9)$. We examined a sample of highly purified haemolysin (containing 10,000 units/ml), kindly provided by Dr. F. C. Knoop, Creighton University, Omaha, Nebraska. The preparation, which was negative for endotoxin in the Limulus gelation assay, demonstrated significant ability as an inhibitor in the ADP platelet aggregation test (PAT), a suitable test method for the enterotoxins that act by means of adenylate-cyclase stimulation (10). Although one should be extremely cautious when attempting to attach any pathophysiological significance to in vitro phenomena, it is not unreasonable to suggest that haemolysin is one of the extracellular products involved in intestinal illness caused by $T$. hyodysenteriae. However, the reported findings are clearly preliminary, and interpretation of the results is limited by the small number of experiments performed. Further detailed investigations will be necessary to explore other virulence factors of the bacterium which collaborate as "toxic" products causing host damage.

\section{Fumarola, G. Miragliotta}

\section{Literature}

1. Douglas, J. G., Crucioli, V.: Spirochaetosis: a remediable cause of diarrhoea and rectal bleeding? Br. Med. J. 283 (1981) 1362.

2. Tompkins, D. S., Waugh, M. A., Cooke, E. M.: Isolation of intestinal spirochaetes from homosexuals. J. Clin. Pathol. 34 (1981) $1385-1387$.

3. Sanna, A., Dettori, G., Grillo, R., Rossi, A., Chiarenza, D.: Isolation and propagation of a strain of Treponema from the human digestive tract. Preliminary report. L'Igiene Moderna 77 (1982) 287-297.

4. Lambert, T., Peter, F., Gourfot, G., Bourlioux, P., Goldstein, F.: Acute enteritis and bacteremia due to Treponema hyodysenteriae. International Symposium "Recent advances in enteric infections". Brugge, September 8-11, 1981, Abstract 15.

5. Nuessen, M. E., Birmingham, J. R., Jones, L. A.: Biological activity of a lipopolysaccharide extracted from Treponema hyodysenteriae. Infect. Immun. 37 (1982) 138-142.
6. Knoop, F. C.: Investigation of a haemolysin produced by enteropathogenic Treponema hyodysenteriae. Infect. Immun. 31 (1981) 193-198.

7. Saheb, S. A., Daigneau-Sylvestre, N., Picard, B.: Comparative study of the hemolysins of Treponema hyodysenteriae and Treponema innocens. Curr. Microbiol. 5 (1981) 87-90.

8. Saheb, S. A., Lallier, R., Massicotte, L., Lafleur, L., Lemieux, S.: Biological activity of Treponema hyodysenteriae hemolysin. Curr. Microbiol. 5 (1981) 91-94.

9. Lemcke, R. M., Burrows, M. R.: Studies on a haemolysin produced by Treponema hyodysenteriae. J. Med. Microbiol. 15 (1982) $205-214$.

10. Fumarola, D., Miragliotta, G.: Platelet aggregation test and enterotoxins from Yersinia enterocolitica. IRCS Med. Sci. 9 (1981) 1033

D. Fumarola, G. Miragliotta, Institute of Medical Microbiology, University of Bari, 1-70124 Bari.

\section{Pharmacokinetics of the Sulphamethoxazole- trimethoprim Combination in Geriatric Patients}

A pilot study was published recently in this journal by Naber et al. (1) on the pharmacokinetics of co-trimoxazole and co-tetroxazine in geriatric patients. Our research team has also performed studies on the pharmacokinetics of the sulphamethoxazole (SMZ) trimethoprim (TMP) combination in young and elderly patients. As our findings are in good agreement with those of the above-mentioned authors, we would like to confirm their conclusion with some of our own data.

Twelve young (average age $20.3 \pm 2.3$ years) and 16 elderly (average age $76.1 \pm 6.0$ years) patients were included in our study. All of them were suffering from acute bacterial infections; their renal and liver functions were normal. The serum creatinine concentrations in both groups were below $1.3 \mathrm{mg} \%$. After fasting overnight, $800 \mathrm{mg}$ sulphamethoxazole and $160 \mathrm{mg}$ trimethoprim (two tablets) were administered. Blood samples were drawn at $1,2,4,7,12$ and $24 \mathrm{~h}$; urine was collected for 24 hours. The serum and urine concentrations of the compounds were determined by the spectrofluorimetric method (2).

According to the one-compartment analysis of the data, the total clearance of SMZ was decreased $(19.39 \pm 5.6$ vs. $28.32 \pm 5.76 \mathrm{ml} / \mathrm{min} ; \mathrm{p}<0.1)$ as a result of reduced elimination $\left(\mathrm{K}_{\mathrm{el}}=0.047 \pm 0.015\right.$ vs. $0.064 \pm 0.01 \mathrm{~h}^{-1}$; $\mathrm{p}<0.05$ ). The urinary excretion of the unchanged SMZ was $117 \pm 28 \mathrm{mg}$ in the elderly and $142 \pm 33 \mathrm{mg} / 24$ hours in the young patients. The decline in the serum concentration curve for TMP was similar in the two groups $\left(\mathrm{K}_{\mathrm{el}}=0.063 \pm 0.028\right.$ vs. $0.069 \pm 0.021 \mathrm{~h}^{-1}$; total clearance $=74.77 \pm 25.6$ vs. $99.15 \pm 31.15 \mathrm{ml} / \mathrm{min}$ ). There was no significant difference between the two groups with respect to the urinary excretion of TMP ( $37.6 \pm 19$ vs. $46.7 \pm 12 \mathrm{mg} / 24$ hours). 